\title{
Screening for Alzheimer's disease in low-educated or illiterate older adults in Brazil: a systematic review
}

\author{
Rastreio para doença de Alzheimer em idosos brasileiros de baixa escolaridade ou \\ analfabetos: revisão sistemática
}

Luciane de Fátima Viola ORTEGA', Ivan APRAHAMIAN ${ }^{2,3}$, Marcus Kiiti BORGES ${ }^{3}$, João de Castilho CAÇÃO4, Mônica Sanches YASSUDA1,5

\begin{abstract}
Cognitive screening instruments are influenced by education and/or culture. In Brazil, as illiteracy and low education rates are high, it is necessary to identify the screening tools with the highest diagnostic accuracy for Alzheimer's disease (AD). Objective: To identify the cognitive screening instruments applied in the Brazilian population with greater accuracy, to detect AD in individuals with a low educational level or who are illiterate. Methods: Systematic search in SciELO, PubMed and LILACS databases of studies that used cognitive screening tests to detect $A D$ in older Brazilian adults with low or no education. Results: We found 328 articles and nine met the inclusion criteria. The identified instruments showed adequate or high diagnostic accuracy. Conclusion: For valid cognitive screening it is important to consider sociocultural and educational factors in the interpretation of results. The construction of specific instruments for the low educated or illiterate elderly should better reflect the difficulties of the Brazilian elderly in different regions of the country.
\end{abstract}

Keywords: Cognition; education; Alzheimer disease; literacy; dementia.

RESUMO

Os instrumentos de rastreio cognitivo sofrem influência educacional e/ou cultural. No Brasil, como as taxas de analfabetismo e baixa escolaridade são altas, é necessário identificar os instrumentos com maior acurácia diagnóstica para a doença de Alzheimer (DA). Objetivo: identificar os instrumentos de rastreio cognitivo aplicados na população brasileira com maior acurácia para detectar DA em indivíduos com baixo nivel de escolaridade ou que são analfabetos. Métodos: Busca sistemática de estudos que utilizaram testes de rastreio cognitivo para detectar DA em idosos brasileiros de baixa escolaridade ou analfabetos, nas bases de dados: SCIELO, PUBMED E LILACS. Resultados: Foram encontrados 328 artigos e 9 preencheram os critérios de inclusão. Os instrumentos identificados apresentaram acurácia diagnóstica adequada ou elevada. Conclusão: Para um rastreio cognitivo válido é importante considerar os fatores socioculturais e educacionais na interpretação dos resultados. A construção de instrumentos epecíficos para idosos de baixa escolaridade ou analfabetos deve ser incentivada para melhor refletir as dificuldades dos idosos brasileiros de diferentes regiões.

Palavras-chave: Cognição; educação; doença de Alzheimer; alfabetização; demência.

Cognitive screening is a strategy to detect cognitive decline in preliminary evaluations as one of the first steps toward establishing a diagnosis of dementia ${ }^{1}$. Among the most frequently used cognitive tests are the Mini-Mental State Examination (MMSE) $)^{2}$, the Clock Drawing Test ${ }^{3}$, and the Verbal Fluency Test (animal or fruit semantic

\footnotetext{
${ }^{1}$ Universidade Estadual de Campinas, Faculdade de Ciências Médicas, Programa de Pós-Graduação em Gerontologia, Campinas SP, Brasil;

${ }^{2}$ Faculdade de Medicina de Jundiaí, Grupo de Investigação em Multimorbidades e Saúde Mental em Idosos, Disciplina de Geriatria e Gerontologia, Jundiaí SP, Brasil; ${ }^{3}$ Universidade de São Paulo, Faculdade de Medicina, Departamento de Psiquiatria, São Paulo SP, Brasil;

${ }^{4}$ Faculdade de Medicina de São José do Rio Preto, Unidade de Geriatria, São José do Rio Preto SP, Brasil;

5Universidade de São Paulo, Escola de Artes, Ciências e Humanidades, São Paulo SP, Brasil.

Luciane de Fátima Viola Ortega iD http://orcid.org/0000-0001-9541-9573; Ivan Aprahamian iD http://orcid.org/0000-0003-3806-7895; Marcus Kiiti Borges (iD) http://orcid.org/0000-0001-8441-9519; João de Castilho Cação iD http://orcid.org/0000-0003-2431-4226; Mônica Sanches Yassuda iD http://orcid.org/0000-0002-9182-2450

Correspondence: Mônica Sanches Yassuda; Rua Tessália Vieira de Camargo, 126 - Cidade Universitária Zeferino Vaz; $13083-887$ Campinas SP, Brasil; E-mail: yassuda@usp.br

Support: Coordenação de Aperfeiçoamento de Pessoal de Nivel Superior - CAPES. Prof. Dr. Ivan Aprahamian recebe Bolsa Produtividade nível 2 do CNPq.

Conflict of interest: There is no conflict of interest to declare

Received 24 May 218; Received in final form 12 December 2018; Accepted 18 December 2018.
} 
categories $)^{4,5}$. However, all of them have limitations, such as the influence of the culture and years of education ${ }^{1}$. Therefore, adjusting the cut-off scores of traditional screening tests according to years of education is warranted to reduce false-positive results $4,6,7,8,9,10,11$.

Education is probably the sociodemographic variable with the greatest impact on the cognitive performance of older adults ${ }^{12}$. The impact of literacy extends across all aspects of cognitive function. Studies have confirmed that formal education has a bearing on cognitive abilities and that adapting and validating screening tests is of paramount importance in the evaluation of individuals of diverse sociocultural backgrounds ${ }^{13,14,15,16}$.

According to the 2010 Brazilian population census, nearly $75 \%$ of Brazilians did not finish elementary school, and around $25 \%$ are unable to read or write a note ${ }^{17}$. Thus, in countries such as Brazil, using strategies less dependent on formal education to screen older adults for cognitive decline is essential.

There is limited information regarding the optimal screening tests for low-educated and illiterate populations. In light of this, the aim of this systematic review was to identify and analyze the cognitive screening tests that have been proposed for detecting Alzheimer's disease (AD) in low-educated or illiterate individuals in Brazil. Alzheimer's disease is the most frequent dementia subtype; therefore, identifying accurate screening tests for $\mathrm{AD}$ in the context of low education is of utmost importance, especially in countries where dementia is underdiagnosed both in primary care and specialized clinics ${ }^{18}$.

\section{METHODS}

The methods for the identification and selection of the articles retrieved from the databases were based on the Preferred Reporting Items for Systematic Review and Meta-Analyses guidelines ${ }^{19}$.

\section{Search strategy}

The search was conducted from inception to November 2018 in the following databases: SciELO, PubMed, and LILACS. The search terms were screening, illiterate (not indexed in MeSH and DeCS), Alzheimer, education, and cognition (indexed in MeSH and DeCS).

The search strategies were based on the descriptors above, using the Boolean operator "AND" in all the combinations. In PubMed the term "screening" was refined to "cognitive screening". In LILACS, the term "illiterate" was added to the "Alzheimer" AND "cognition" overlap. Next, the term "education" was added due to the large number of articles retrieved that did not have relevance to the search. The filters "elder", "Alzheimer's disease", "Brazil" and "full text" were used to refine the search.
As 19 selected articles were read in full, 12 new articles were identified that fulfilled the search criteria but had not been identified. These were added manually. Articles in English, Portuguese, and Spanish were accepted. Any disagreement about a study's selections by any author of this review was judged and resolved by consensus among the authors involved.

\section{Inclusion criteria}

Only those Brazilian articles that were strictly related to cognitive screening tools with a low educated and/or illiterate population, and with the objective of detecting Alzheimer's disease, were eligible for the review. Articles on diagnostic accuracy, comparison of tests and new instruments were included in this review if the researchers answered "yes" to the following questions of our research protocol: Is the article about a screening instrument? Is the focus on a population with low education/illiteracy? Is the goal to detect Alzheimer's disease? Was the study conducted in Brazil? Does the study include measures of sensitivity and specificity?

Articles that evaluated older adults with other educational levels were selected only if the study included a sample of individuals who were illiterate or had low education. Studies on instruments that assessed a specific cognitive function were only accepted if the focus was on low-educated/ illiterate older adults.

\section{Exclusion criteria}

The articles excluded by the title and abstract had the following justifications: they evaluated other pathologies such as bipolar affective disorder, stroke, multiple sclerosis, Parkinson's disease, vascular dementia; the tests used were not considered screening instruments; the study included only descriptions of community samples or long-term care institutions and only discussed the relevance of education/ literacy in $\mathrm{AD}$. Studies involving neuropsychological batteries were also excluded.

\section{Article selection process}

A total of 5,533 articles were identified. A title screen led to the exclusion of 5,217 articles that were unrelated to the study topic. Of the 328 remaining articles, 297 were excluded after the abstracts were screened. Nineteen articles were read throughout, and another 12 additional articles were included. After reading 31 full texts, 22 articles were excluded because their main focus was not related to the topic. Finally, nine studies were selected for the systematic review, as summarized in the flow chart (Figure).

The initial search was carried out by two authors who prescreened the titles and abstracts. Subsequently, the eligible articles were read by two authors who discussed eligibility for inclusion in the review. The nine articles selected were included by agreement between the two authors. 


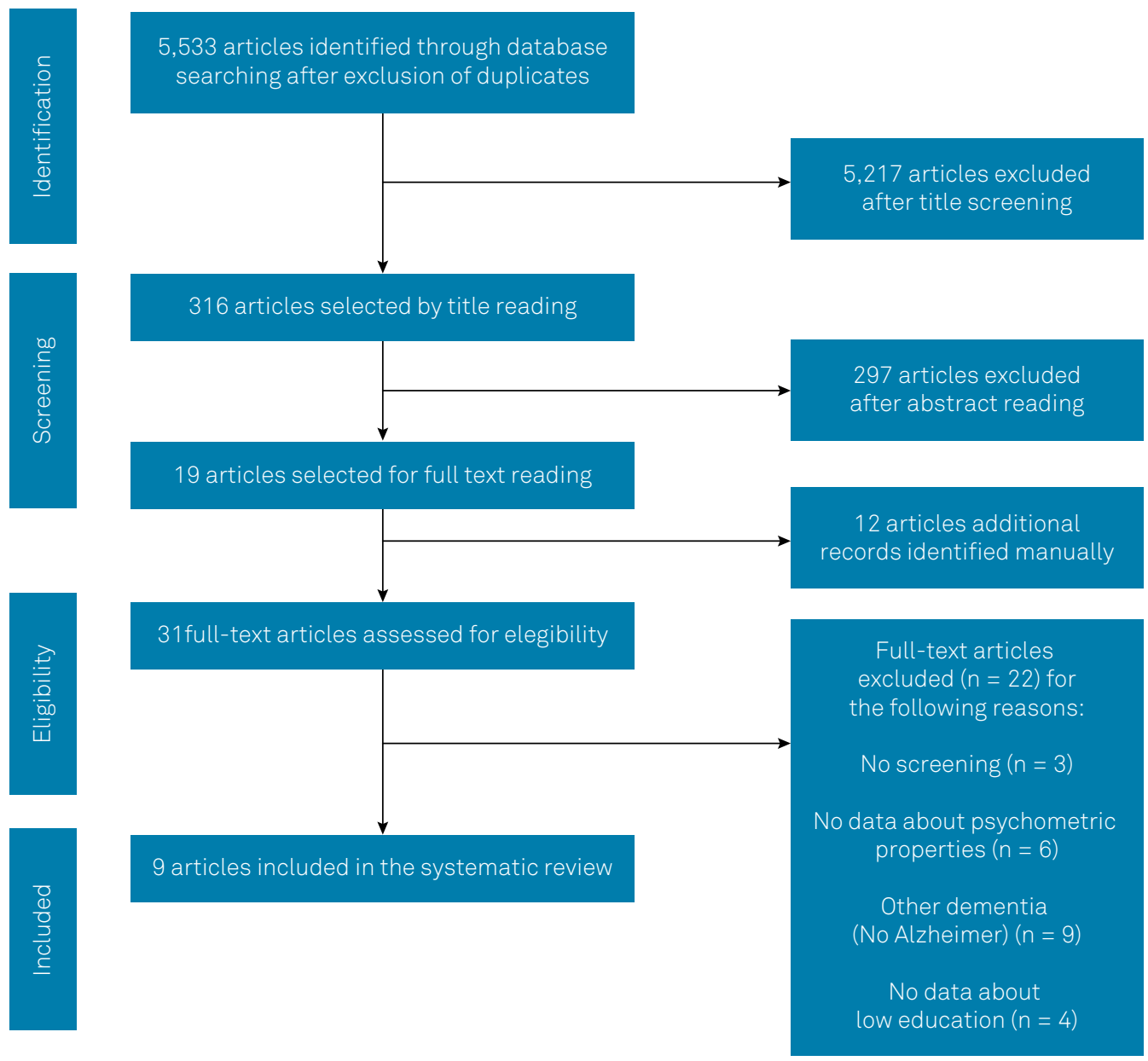

Figure. Identification and selection of the articles in the present review

\section{RESULTS}

The articles were included if the focus of the study was exclusively cognitive screening instruments in low education/illiterate seniors for the detection of Alzheimer's disease in Brazil.

Nine articles that met the inclusion criteria were identified. The articles are listed in alphabetical order in the Table.

Aprahamian et al. ${ }^{3}$ had evaluated the diagnostic accuracy of the Clock Drawing Test for $\mathrm{AD}$ diagnosis using different scoring methods and investigated whether the combination of the MMSE with the Clock Drawing Test increased accuracy compared with the Cambridge Cognition Examination. The results showed high sensitivity and specificity of the Clock Drawing Test to identify AD. The combination of the Clock Drawing Test and the MMSE increased sensitivity and specificity in older adults with a lower educational level ${ }^{3}$.

In another study, Aprahamian et al. ${ }^{20}$ examined whether the Cambridge Cognition Examination could be used as a precise screening tool for $\mathrm{AD}$ diagnosis across varying levels of education, with no illiterate individuals included. The results were favorable, but the value of using a single and predetermined cut-off point for $\mathrm{AD}$ screening was debatable, considering that the Cambridge Cognition Examination could be influenced by sociodemographic characteristics such as age and education. Therefore, the authors suggested cut-off scores for each educational level ${ }^{20}$.

Only one article focusing on a combination of several instruments fulfilled the inclusion criteria. Aprahamian et al. ${ }^{21}$ combined well-established cognitive screening tests, the MMSE, Clock Drawing Test, Verbal Fluency test, and the Pfeffer Functional Activities Questionnaire to determine which of them, individually and in combination, would best discriminate between illiterate older adults with and without $\mathrm{AD}$. In their study, the best individual screening tools for illiterate older adults were the MMSE and the Pfeffer Functional Activities Questionnaire. The most sensitive combination was the MMSE and Pfeffer Functional Activities Questionnaire (94.1\%), whereas the most specific was the MMSE and Clock Drawing Test (89\%). These results suggested that these traditional tools are appropriate for $\mathrm{AD}$ screening among illiterate older adults ${ }^{21}$.

In the validation article of the Rowland Universal Dementia Assessment Scale ${ }^{22}$ for use in Brazil, the authors also assessed the issue of educational level. They stratified the sample of controls and $\mathrm{AD}$ patients by low ( $\leq 4$ years) and 


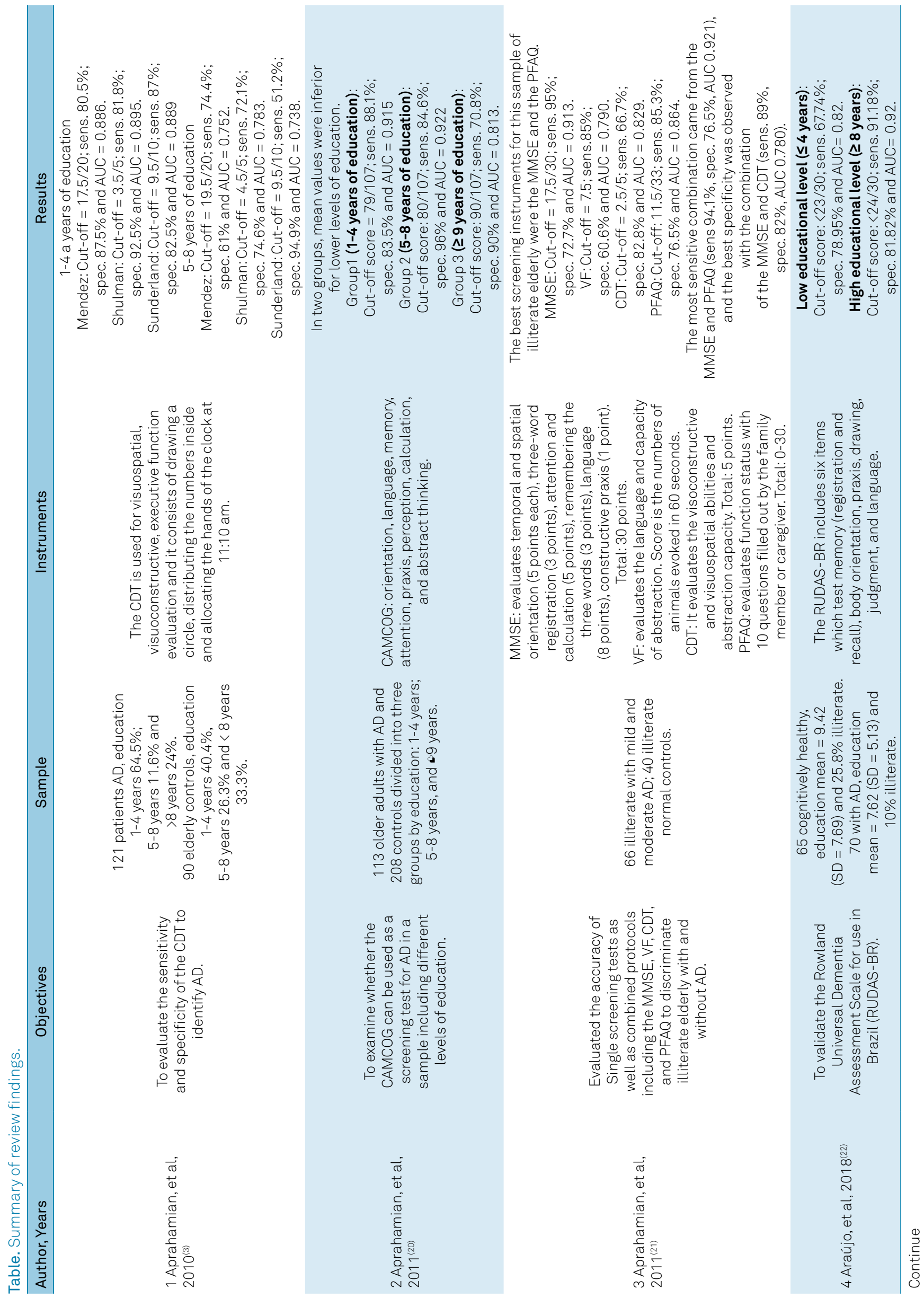




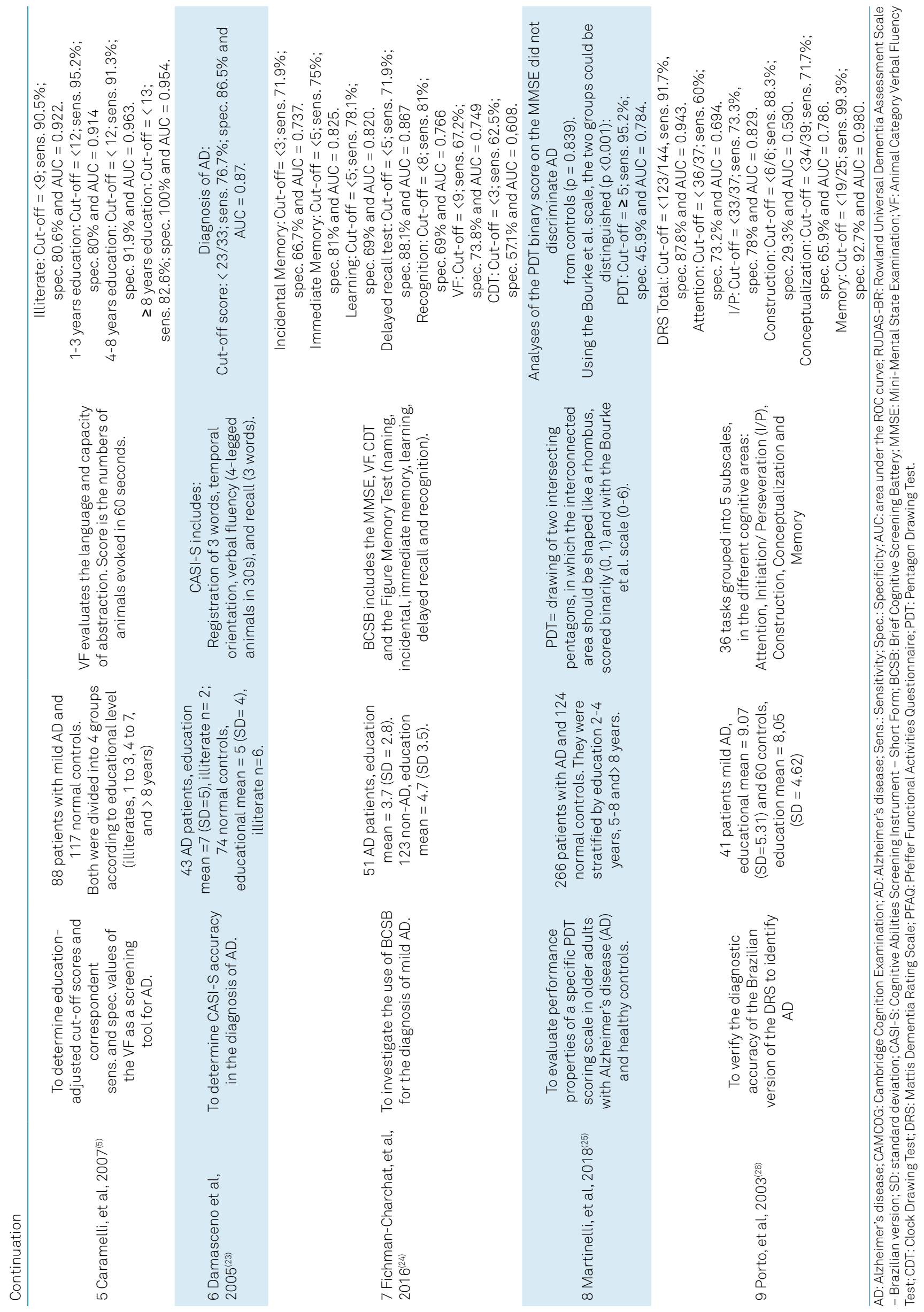


high ( $\geq 8$ years) educational levels to evaluate the accuracy of the Rowland Universal Dementia Assessment Scale-Brazil against the MMSE ${ }^{22}$. The ideal cut-off score of the Brazilian version coincided with the one proposed for the original instrument $\left(<23\right.$ points) ${ }^{27}$ and the sensitivity and specificity were similar to those observed for the MMSE. The Rowland Universal Dementia Assessment Scale-Brazil seems to be as accurate as the MMSE in classifying $\mathrm{AD}$. The use of the former scale may improve the cognitive screening of older adults in different cultures, as it was easily comprehended by participants of different educational levels after direct translation into Brazilian Portuguese. Also, it was not significantly influenced by educational level ${ }^{22}$.

The Verbal Fluency test (animals/minute) is easy and quick to administer. Nevertheless, it was greatly influenced by education ${ }^{28}$. The study by Caramelli et al. ${ }^{5}$ aimed to determine the optimal cut-off points according to educational level. The results showed that for the illiterate group the cut-off was lower (nine animals) compared with the other educational groups. There was no significant difference between the groups of 1-3 years and 4-7 years of education (12 animals as cut-off). For those with more than eight years of education, the cut-off was higher (13 animals). Results suggested that the Verbal Fluency test was a highly accurate screening test for mild $\mathrm{AD}$ across different educational levels, but there is a need to use education-specific cut-off scores ${ }^{5}$.

The Cognitive Abilities Screening Instrument-Short Form is a very brief instrument evaluating temporal orientation, verbal fluency in 30 seconds (four-legged animals) and memorization of three words ${ }^{29}$. In this study, the authors added the Pentagon Drawing Test, part of the MMSE, to verify whether the diagnostic accuracy increased ${ }^{23}$ due to the relevance of constructive praxis evaluation as a predictor of cognitive decline ${ }^{30}$. An effect of education was seen only in the recall subtest, and all Cognitive Abilities Screening Instrument-Short Form subtests could discriminate $\mathrm{AD}$ patients from controls. The diagnostic accuracy was high, particularly the specificity among people aged 70 years or above. The instrument's accuracy was not improved by the addition of the Pentagon Drawing Test, and this task was very difficult for people with low education ${ }^{23}$.

The Brief Cognitive Screening Battery includes the Figure Memory Test, Verbal Fluency and the Clock Drawing Test, which may be applied with the MMSE for the detection of $\mathrm{AD}^{31}$. Fichman-Charchat et al. ${ }^{24}$ investigated the use of the Brief Cognitive Screening Battery for the diagnosis of mild $\mathrm{AD}$ in a geriatric outpatient unit of a public hospital. All the measures in the battery were influenced by age, and the Verbal Fluency and the Clock Drawing Test were correlated with educational level. The Figure Memory Test measured, in particular, the delayed recall measure, which showed greater ability to identify elderly patients with probable AD. The Brief Cognitive Screening Battery seemed to contribute to an $\mathrm{AD}$ diagnosis in groups with heterogeneous educational levels ${ }^{24}$.
The Pentagon Drawing Test contained in the MMSE assesses constructional praxis. Martinelli et al..$^{25}$ studied the accuracy of the Pentagon Drawing Test binary score and the six-point score suggested by Bourke et al. ${ }^{32}$ in patients with $\mathrm{AD}$ and healthy controls. The results showed that the Pentagon Drawing Test discriminated healthy controls from patients with $\mathrm{AD}$, although with relatively low specificity. It also identified different clinical stages of the disease. The six-point score showed a significant correlation with the MMSE, the Clock Drawing Test, and the Cambridge Cognition Examination ${ }^{25}$.

The Mattis Dementia Rating Scale is a longer cognitive screening battery widely used in the assessment of general cognitive status ${ }^{33}$. Porto et al. ${ }^{26}$ verified that the Mattis Dementia Rating Scale showed adequate diagnostic accuracy to diagnose mild $\mathrm{AD}$. The effects of education were more evident than the effects of age ${ }^{26}$.

\section{DISCUSSION}

The aim of the present systematic review was to identify Brazilian studies for $\mathrm{AD}$ screening in older adults who were either illiterate or had little education. Due to the educational and sociocultural heterogeneity found in developing countries, evaluating older adults using the screening tests commonly administered in developed countries may lead to less accurate results. Therefore, the present review aimed to identify the most accurate instruments for $\mathrm{AD}$ identification in populations with heterogeneous educational backgrounds.

It is essential to develop new tools that reflect the reality of the illiterate or low education population in order to improve the accuracy of cognitive screening. Towards this end, we identified that the Brief Cognitive Screening Battery Figure Memory Test, developed in Brazil, adequately screens for $\mathrm{AD}$ among those with low education. This is an episodic memory test based on 10 black and white pictures of common objects, easily named by individuals across all educational levels ${ }^{31}$.

Research on the MMSE, included in this review, indicated that adjusting the cut-off according to the educational level of the patient led to adequate accuracy indices among those with low education. Yet, the education bias in the MMSE might also be resolved with a more refined adaptation of the test for the low-educated population, which has not yet been carried out in Brazi ${ }^{34,35}$.

Most of the studies found in this review compared the diagnostic accuracy of new instruments, such as the Rowland Universal Dementia Assessment Scale, or combinations of traditional screening instruments, with the accuracy of the MMSE. These studies have indicated that longer instruments, such as the Mattis Dementia Rating Scale and the Cambridge Cognition Examination, and shorter ones, such as the Cognitive 
Abilities Screening Instrument-Short Form, may be just as accurate in detecting $\mathrm{AD}$ in populations with little educat ion $^{3,20,21,22,25,36,37,38,39,40,41,42,43,44}$. When combined with the MMSE, these instruments may increase the diagnostic accuracy ${ }^{3}$.

In this review, some selected studies focused on multiple domain batteries, which showed high diagnostic accuracy for $\mathrm{AD}$ across different levels of education. The Mattis Dementia Rating Scale and the Cambridge Cognition Examination total scores were highly sensitive and specific for $\mathrm{AD}$, even among those with low education. One of the advantages of these longer multi-domain batteries is that they generate separate scores for each cognitive domain assessed. However, the Mattis Dementia Rating Scale sub-test analyses revealed that the construction and attention subdomains had reduced accuracy in the group with lower education. It is also necessary to highlight some limitations of the available data regarding these two instruments. Both have been validated in samples in São Paulo, with clinical samples that may not be representative of older adults in different regions of Brazil ${ }^{20,26}$. In addition, scores may still depend on the years of education, as evidenced by the high rates of errors in the items involving reading and writing abilities, in the Cambridge Cognition Examination ${ }^{20}$. Consequently, the proposed adaptations may not be entirely suitable for the illiterate population ${ }^{3,45,46,47}$.

The Cognitive Abilities Screening Instrument-Short Form is a short multi-domain test, reduced from its longer original version, which has been found to be highly accurate for $\mathrm{AD}^{23}$ and dementia ${ }^{48}$ identification in Brazil. Although the Cognitive Abilities Screening Instrument-Short Form does not offer subdomain scores, it is an interesting screening option as it is quick to apply; it considers partial performance scores, and the three-item memory test is more difficult than the one in the MMSE as it includes abstract substantives. There are three alternate versions to reduce the retest effect, and the recall phase also allows for semantic cueing. In the study by Damasceno et al. ${ }^{23}$, the authors verified the effect of education on the memory subtest, which was explained by the poor performance of the illiterate group compared with the other groups. As for the added test of constructive praxis (the Pentagon Drawing Test - not part of the Cognitive Abilities Screening Instrument), a difference was also found between the illiterate group and the other groups, but the inclusion of the Pentagon Drawing Test did not increase the diagnostic accuracy of the Cognitive Abilities Screening Instrument-Short Form. In addition to being a very difficult task for individuals with low education, it increased the evaluation time ${ }^{23}$.

Another instrument that also evaluated various cognitive functions is the Rowland Universal Dementia Assessment Scale-Brazil ${ }^{22}$. The original scale was developed in Australia as an easily-administered test for detecting dementia across different cultures ${ }^{27}$. Using tasks that do not bring cultural differences into them was key, so that translation and adaptation would not require major modifications from the original version ${ }^{49}$. The test involves the memorization of four grocery items, body orientation commands such as "touch your left elbow with your right hand", a fist-palm alternation task, cube copying, problem solving ("what would you do to cross a busy street safely") and a verbal fluency animal category. The Brazilian version of the test demonstrated high diagnostic accuracy for $\mathrm{AD}$, although accuracy was lower for the group with four or less years of education.

Illiterate individuals have unique cognitive characteristics and they have sharp skills that enable them to adapt and maintain the ability to solve the problems of daily life in a pragmatic way. In these cases, cognitive testing should emphasize the practical tasks that constitute part of the life experience of these older individuals. The more the tests reflect activities of daily living, the more reliable the evaluation would be. The same is true for groups with a very particular cultural background, such as Brazilian indigenous populations. It is critical to formulate test questions according to the life experiences and reality of these populations. In developed countries, researchers have invested in strategies to evaluate immigrants ${ }^{50}$ or culturally-diverse populations, as is the case of aboriginals in Australia ${ }^{51}$.

The Brief Cognitive Screening Battery was developed by Nitrini et al. ${ }^{31}$ as a screening tool that was fair to those patients with less education. It includes the Figure Memory Test, the Clock Drawing Test and Verbal Fluency animal category. Fichman-Charchat et al. ${ }^{24}$ documented that each component contributed to the $\mathrm{AD}$ diagnosis, in a clinical sample that had heterogeneous clinical, cognitive and demographic characteristics, reflecting the context of several outpatient clinics in low income countries. In this study the Verbal Fluency and the Clock Drawing Test were significantly affected by education and had a lower diagnostic accuracy ${ }^{24}$. The Brief Cognitive Screening Battery Figure Memory Test had the highest accuracy for AD.

Several studies have suggested that tests of executive functions may be more influenced by education ${ }^{28,52,53,54}$. Caramelli et al. $^{5}$ demonstrated that the Verbal Fluency animal category, a traditional measure of executive function, had a high accuracy for AD, as long as education adjusted cut-off scores were used. Although the Verbal Fluency test may be seen as an easy cognitive task, high scores may require complex cognitive processing, such as category switching. These demands may be complex for low-educated or illiterate individuals ${ }^{26}$.

Most cognitive screening tests include at least one measure of visuoconstructional ability (the Cognitive Abilities Screening Instrument-Short Form is an exception). However, such tasks usually depend on previous educational experiences, especially pencil and paper drawing. The Clock Drawing Test is a traditional screening test that relies, to a certain extent, on semantic memory (knowledge of how a clock works), but also on executive functions, such as 
planning, and on drawing abilities ${ }^{11,21,55}$. Aprahamian et al. ${ }^{3}$ have shown that the Clock Drawing Test may contribute to an $\mathrm{AD}$ diagnosis among older adults with low education. However, the authors acknowledged that their findings might not be representative of other regions in Brazil, as the sample came from a private clinic in a city with a high human development index. In fact, other Brazilian studies have suggested that the Clock Drawing Test may have limited diagnostic ability for $\mathrm{AD}^{24}$ or dementia ${ }^{46}$ diagnoses in the context of low education.

Some studies have shown that visuospatial tasks involving drawings are particularly difficult for older adults with little or no formal education ${ }^{52,53,54}$. Other studies have underlined the need for caution when interpreting Clock Drawing Test findings, as the level of education is a potential source of bias $^{46,56}$. Yet, other studies have shown that adapted forms of assessment of constructive praxis, such as the Stick Design Test or the Adpated Taylor Figure, may be an important complement to the cognitive screening of older adults with low education ${ }^{39,57}$.

The present review also included a study that analyzed the contribution of the MMSE Pentagon Drawing Test ${ }^{25}$. The Bourke scale for scoring the Pentagon Drawing Test proved to be able to distinguish the control from the $\mathrm{AD}$ group, although its sensitivity was low. Applying the Bourke scoring scale for analysis of this subtest may contribute to the assessment of visuoconstruction in the MMSE that is not allowed by the usual binary scoring method ${ }^{25}$.

An effective strategy to improve diagnostic accuracy may include combining tasks that are known to be less influenced by education in a single instrument ${ }^{36,50}$ or combining tests for improved accuracy in detecting dementia ${ }^{21,42,44}$. Aprahamian et al..$^{25}$ combined the MMSE, the Clock Drawing Test, Verbal Fluency test and the Pfeffer Functional Activities Questionnaire to assess illiterate individuals with and without $\mathrm{AD}$. The results suggest that these tests remain highly accurate among illiterate elderly and may aid in identifying positive $\mathrm{AD}$ in patients, when appropriate cut-off scores are used. However, the authors underscored the need to develop new testing and screening approaches with emphasis on regional diversity.

Although the reviewed studies have suggested that traditional screening tests may be useful when used among individuals with limited education, tests that take into account the sociocultural and educational backgrounds of patients may better reflect their daily difficulties. Such tests may include practical questions, as the ones proposed by LoGiudice et al..$^{51}$ in the Kimberley Indigenous Cognitive Assessment short version, such as using a comb, memory tasks with common pictures, verbal fluency involving familiar animals, recalling the day of retirement payment.

Overall, the reviewed studies highlight that social and cultural factors should be taken into account when interpreting cognitive screening results, and that screening approaches should overcome the impact of educational and sociocultural heterogeneity on cognition ${ }^{21,41,45,58}$, either by the adjustment of cut-off scores or appropriate test construction or adaptation ${ }^{59,60}$.

The present review has the following limitation. The search was restricted to $\mathrm{AD}$, and studies that focused on other dementia types or dementia in general were not selected. Future reviews could enlarge the article selection by using the search term dementia instead of $\mathrm{AD}$.

\section{CONCLUSION}

The articles found in the present systematic review included instruments, batteries, and combinations that could be used to identify dementia in low-educated or illiterate individuals. The present review underscored the importance of taking into consideration sociocultural and educational factors when interpreting the results of screening tests for dementia. In addition, combining tests may augment the diagnostic accuracy for AD. Further studies could propose novel instruments targeting older adults of low education based on stimuli and tasks that are common in the Brazilian cultural context.

\section{References}

1. Shulman KI, Herrmann N, Brodaty H, Chiu H, Lawlor B, Ritchie K, et al. IPA survey of brief cognitive screening instruments. Int Psychogeriatr. 2006 Jun;18(2):281-94. https://doi.org/10.1017/S1041610205002693

2. Folstein MF, Folstein SE, McHugh PR. "Mini-mental state". A practical method for grading the cognitive state of patients for the clinician. J Psychiatr Res. 1975 Nov;12(3):189-98. https://doi.org/10.1016/0022-3956(75)90026-6

3. Aprahamian I, Martinelli JE, Neri AL, Yassuda MS. The accuracy of the Clock Drawing Test compared to that of standard screening tests for Alzheimer's disease: results from a study of Brazilian elderly with heterogeneous educational backgrounds. International psychogeriatrics / IPA. 2010;22(1):64-71. https://doi.org/10.1017/S1041610209991141
4. Silva T, Yassuda MS, Guimarães VV, Florindo AA. Fluência verbal e variáveis sociodemográficas no processo de envelhecimento: um estudo epidemiológico. Psicol Reflex Crit. 2011;24(4):739-46. https://doi.org/10.1590/S0102-79722011000400014

5. Caramelli P, Carthery-Goulart MT, Porto CS, CharchatFichman H, Nitrini R. Category fluency as a screening test for Alzheimer disease in illiterate and literate patients. Alzheimer Dis Assoc Disord. 2007 Jan-Mar;21(1):65-7. https://doi.org/10.1097/WAD.0b013e31802f244f

6. Almeida OP. [Mini mental state examination and the diagnosis of dementia in Brazil]. Arq Neuropsiquiatr. 1998 Sep;56 3B:605-12. Portuguese. https://doi.org/10.1590/S0004-282X1998000400014 
7. Machado O, Correia SM, Mansur LL. [Performance of normal Brazilian adults in a semantic test: effect of literacy]. Pro Fono. 2007 Jul-Sep;19(3):289-94.Portuguese. https://doi.org/10.1590/S0104-56872007000300007

8. Bertolucci PH, Brucki SM, Campacci SR, Juliano Y. O [The Mini-Mental State Examination in a general population: impact of educational status]. Arq Neuropsiquiatr. 1994 Mar;52(1):1-7. Portuguese. https://doi.org/10.1590/S0004-282X1994000100001

9. Brucki SM, Nitrini R, Caramelli P, Bertolucci PH, Okamoto IH. [Suggestions for utilization of the mini-mental state examination in Brazil]. Arq Neuropsiquiatr. 2003 Sep;61 3B:777-81. Portuguese. https://doi.org/10.1590/S0004-282X2003000500014

10. Brito-Marques PR, Cabral-Filho JE. The role of education in mini-mental state examination: a study in Northeast Brazil. Arq Neuropsiquiatr. 2004 Jun;62(2a 2A):206-11. https://doi.org/10.1590/S0004-282X2004000200003

11. Aprahamian I, Martinelli JE, Yassuda MS. Doença de Alzheimer em idosos com baixa escolaridade: o teste do Desenho do Relógio pode ser útil no rastreio cognitivo? Rev Soc Bras Clin Med. 2008;6(4):130-4.

12. Ostrosky-Solis F, Ramirez M, Ardila A. Effects of culture and education on neuropsychological testing: a preliminary study with indigenous and nonindigenous population. Appl Neuropsychol. 2004;11(4):188-95. https://doi.org/10.1207/s15324826an1104_3

13. Ardila A, Rosselli M, Puente AE. Neuropsychological evaluation of the Spanish speaker. Springer Science \& Business Media; 1994. https://doi.org/10.1007/978-1-4899-1453-8

14. Rosselli M, Ardila A. The impact of culture and education on non-verbal neuropsychological measurements: a critical review. Brain Cogn. 2003 Aug;52(3):326-33. https://doi.org/10.1016/S0278-2626(03)00170-2

15. Rosselli M, Ardila A. Effects of age, education, and gender on the Rey-Osterrieth Complex Figure. Clin Neuropsychol. 1991;5(4):370-6. https://doi.org/10.1080/13854049108404104

16. Ardila A, Rosselli M, Rosas P. Neuropsychological assessment in illiterates: visuospatial and memory abilities. Brain Cogn. 1989 Nov;11(2):147-66. https://doi.org/10.1016/0278-2626(89)90015-8

17. Instituto Brasileiro de Geografia e Estatística - IBGE. Censo demográfico: características gerais da população, religião e pessoas com deficiências. Rio de Janeiro Instituto Brasileiro de Geografia e Estatística; 2010.

18. Jacinto AF, Brucki S, Porto CS, Martins MA, Nitrini R. Detection of cognitive impairment in the elderly by general internists in Brazil. Clinics (São Paulo). 2011;66(8):1379-84. https://doi.org/10.1590/S1807-59322011000800012

19. Moher D, Shamseer L, Clarke M, Ghersi D, Liberati A, Petticrew M, et al. Preferred reporting items for systematic review and metaanalysis protocols (PRISMA-P) 2015 statement. Syst Rev. 2015 Jan;4(1):1. https://doi.org/10.1186/2046-4053-4-1

20. Aprahamian I, Martinelli JE, Cecato J, Izbicki R, Yassuda MS. Can the CAMCOG be a good cognitive test for patients with Alzheimer's disease with low levels of education? Int Psychogeriatr. 2011 Feb;23(1):96-101. https://doi.org/10.1017/S104161021000116X

21. Aprahamian I, Martinelli JE, Cecato J, Yassuda MS. Screening for Alzheimer's disease among illiterate elderly: accuracy analysis for multiple instruments. J Alzheimers Dis. 2011;26(2):221-9. https://doi.org/10.3233/JAD-2011-110125

22. Araujo NB, Nielsen TR, Engedal K, Barca ML, Coutinho ES, Laks J. Diagnosing dementia in lower educated older persons: validation of a Brazilian Portuguese version of the Rowland Universal Dementia Assessment Scale (RUDAS). Rev Bras Psiquiatr. 2018 Jul-Sep;40(3):264-9. https://doi.org/10.1590/1516-4446-2017-2284
23. Damasceno A, Delicio AM, Mazo DF, Zullo JF, Scherer P, Ng RT, et al. [Validation of the Brazilian version of mini-test CASI-S]. Arq Neuropsiquiatr. 2005 Jun;63(2b 2B):416-21.Portuguese. https://doi.org/10.1590/S0004-282X2005000300010

24. Fichman-Charchat H, Miranda CV, Fernandes CS, Mograbi D, Oliveira RM, Novaes R, et al. Brief Cognitive Screening Battery (BCSB) is a very useful tool for diagnosis of probable mild Alzheimer's disease in a geriatric clinic. Arq Neuropsiquiatr. 2016 Feb;74(2):149-54. https://doi.org/10.1590/0004-282X20150202

25. Martinelli JE, Cecato JF, Martinelli MO, de Melo BA, Aprahamian I. Performance of the Pentagon Drawing test for the screening of older adults with Alzheimer's dementia. Dement Neuropsychol. 2018 Jan-Mar;12(1):54-60. https://doi.org/10.1590/1980-57642018dn12-010008

26. Porto CS, Fichman HC, Caramelli P, Bahia VS, Nitrini R. Brazilian version of the Mattis dementia rating scale: diagnosis of mild dementia in Alzheimer's disease. Arq Neuropsiquiatr. 2003 Jun;61 2B:339-45. https://doi.org/10.1590/S0004-282X2003000300004

27. Storey JE, Rowland JT, Basic D, Conforti DA, Dickson HG. The Rowland Universal Dementia Assessment Scale (RUDAS): a multicultural cognitive assessment scale. Int Psychogeriatr. 2004 Mar;16(1):13-31. https://doi.org/10.1017/S1041610204000043

28. Brucki SM, Rocha MS. Category fluency test: effects of age, gender and education on total scores, clustering and switching in Brazilian Portuguese-speaking subjects. Braz J Med Biol Res. 2004 Dec;37(12):1771-7. https://doi.org/10.1590/S0100-879X2004001200002

29. Teng EL, Hasegawa K, Homma A, Imai Y, Larson E, Graves A, et al. The Cognitive Abilities Screening Instrument (CASI): a practical test for cross-cultural epidemiological studies of dementia. Int Psychogeriatr. 1994;6(1):45-58. https://doi.org/10.1017/S1041610294001602

30. Jacobs DM, Sano M, Dooneief G, Marder K, Bell KL, Stern Y. Neuropsychological detection and characterization of preclinical Alzheimer's disease. Neurology. 1995 May;45(5):957-62. https://doi.org/10.1212/WNL.45.5.957

31. Nitrini R, Caramelli P, Porto CS, Charchat-Fichman H, Formigoni AP, Carthery-Goulart MT, et al. Brief cognitive battery in the diagnosis of mild Alzheimer's disease in subjects with medium and high levels of education. Dement Neuropsychol. 2007 Jan-Mar;1(1):32-6. https://doi.org/10.1590/S1980-57642008DN10100006

32. Bourke J, Castleden CM, Stephen R, Dennis M. A comparison of clock and pentagon drawing in Alzheimer's disease. Int J Geriatr Psychiatry. 1995;10(8):703-5. https://doi.org/10.1002/gps.930100811

33. Mattis S. Mental status examination for organic mental syndrome in the elderly patients. Geriatric Psychiatry A Hand Book for Psychiatrics and Primary Care Physicians; 1976.

34. Bernstein IH, Lacritz L, Barlow CE, Weiner MF, DeFina LF. Psychometric evaluation of the Montreal Cognitive Assessment (MoCA) in three diverse samples. Clin Neuropsychol. 2011 Jan;25(1):119-26. https://doi.org/10.1080/13854046.2010.533196

35. Rossetti HC, Lacritz LH, Cullum CM, Weiner MF. Normative data for the Montreal Cognitive Assessment (MoCA) in a population-based sample. Neurology. 2011 Sep;77(13):1272-5. https://doi.org/10.1212/WNL.0b013e318230208a

36. Apolinario D, Lichtenthaler DG, Magaldi RM, Soares AT, Busse AL, Amaral JR, et al. Using temporal orientation, category fluency, and word recall for detecting cognitive impairment: the 10-point cognitive screener (10-CS). Int J Geriatr Psychiatry. 2016 Jan;31(1):412. https://doi.org/10.1002/gps.4282

37. Babacan-Yildiz G, Isik AT, Ur E, Aydemir E, Ertas C, Cebi M, et al. COST: cognitive State Test, a brief screening battery for Alzheimer disease in illiterate and literate patients. Int Psychogeriatr. 2013 Mar;25(3):403-12. https://doi.org/10.1017/S1041610212001780 
38. Caldas VV, Zunzunegui MV, Freire AN, Guerra RO. Translation, cultural adaptation and psychometric evaluation of the Leganés cognitive test in a low educated elderly Brazilian population. Arq Neuropsiquiatr. 2012 Jan;70(1):22-7. https://doi.org/10.1590/S0004-282X2012000100006

39. de Paula JJ, Costa MV, Bocardi MB, Cortezzi M, De Moraes EN, Malloy-Diniz LF. The Stick Design Test on the assessment of older adults with low formal education: evidences of construct, criterion-related and ecological validity. Int Psychogeriatr. 2013 Dec;25(12):2057-65. https://doi.org/10.1017/S1041610213001282

40. Park S, Park SE, Kim MJ, Jung HY, Choi JS, Park KH, et al. Development and validation of the Pictorial Cognitive Screening Inventory for illiterate people with dementia. Neuropsychiatr Dis Treat. 2014 Sep;10:1837-45. https://doi.org/10.2147/NDT.S64151

41. Rezende GP, Cecato J, Martinelli JE. Cognitive abilities screening instrument-short form, mini-mental state examination and functional activities questionnaire in the illiterate elderly. Dement Neuropsychol. 2013 Oct-Dec;7(4):410-5. https://doi.org/10.1590/S1980-57642013DN74000009

42. Rideaux T, Beaudreau SA, Fernandez S, O'Hara R. Utility of the abbreviated Fuld Object Memory Evaluation and MMSE for detection of dementia and cognitive impairment not dementia in diverse ethnic groups. J Alzheimers Dis. 2012;31(2):371-86. https://doi.org/10.3233/JAD-2012-112180

43. Radford K, Mack HA, Draper B, Chalkley S, Delbaere K, Daylight G, et al. Comparison of three cognitive screening tools in older urban and regional Aboriginal Australians. Dement Geriatr Cogn Disord. 2015;40(1-2):22-32. https://doi.org/10.1159/000377673

44. Tappen RM, Rosselli M, Engstrom G. Use of the MC-FAQ and MMSE$F A Q$ in cognitive screening of older African Americans, Hispanic Americans, and European Americans. Am J Geriatr Psychiatry. 2012 Nov;20(11):955-62. https://doi.org/10.1097/JGP.0b013e31825d0935

45. Paradela EM, Lourenço RA. Is the Cambridge Cognitive Examination - revised a good tool for detection of dementia in illiterate Brazilian older adults? Geriatr Gerontol Int. 2014 Oct;14(4):763-8. https://doi.org/10.1111/ggi.12161

46. Lourenço RA, Ribeiro-Filho ST, Moreira IF, Paradela EM, Miranda AS. The Clock Drawing Test: performance among elderly with low educational level. Br J Psychiatry. 2008 Dec;30(4):309-15. https://doi.org/10.1590/S1516-44462008000400002

47. Kochhann R, Cerveira MO, Godinho C, Camozzato A, Chaves ML. Evaluation of Mini-Mental State Examination scores according to different age and education strata, and sex, in a large Brazilian healthy sample. Dement Neuropsychol. 2009 Apr-Jun;3(2):88-93. https://doi.org/10.1590/S1980-57642009DN30200004

48. de Oliveira GM, Yokomizo JE, Vinholi e Silva LS, Saran LF, Bottino CM, Yassuda MS. The applicability of the cognitive abilities screening instrument-short (CASI-S) in primary care in Brazil. Int Psychogeriatr. 2016 Jan;28(1):93-9. https://doi.org/10.1017/S1041610215000642

49. Nielsen TR, Vogel A, Gade A, Waldemar G. Cognitive testing in non-demented Turkish immigrants-comparison of the RUDAS and the MMSE. Scand J Psychol. 2012 Dec;53(6):455-60. https://doi.org/10.1111/sjop.12018

50. Nielsen TR, Vogel A, Waldemar G. Comparison of performance on three neuropsychological tests in healthy Turkish immigrants and Danish elderly. Int Psychogeriatr. 2012 Sep;24(9):1515-21. https://doi.org/10.1017/S1041610212000440

51. LoGiudice D, Strivens E, Smith K, Stevenson M, Atkinson D, Dwyer A, et al. The KICA Screen: the psychometric properties of a shortened version of the KICA (Kimberley Indigenous Cognitive Assessment). Australas J Ageing. 2011 Dec;30(4):215-9. https://doi.org/10.1111/j.1741-6612.2010.00486.x

52. Ardila A, Bertolucci PH, Braga LW, Castro-Caldas A, Judd T, Kosmidis $\mathrm{MH}$, et al. Illiteracy: the neuropsychology of cognition without reading. Arch Clin Neuropsychol. 2010 Dec;25(8):689-712. https://doi.org/10.1093/arclin/acq079

53. Baiyewu O, Unverzagt FW, Lane KA, Gureje O, Ogunniyi A, Musick B, et al. The Stick Design test: a new measure of visuoconstructional ability. J Int Neuropsychol Soc. 2005 Sep;11(5):598-605. https://doi.org/10.1017/S135561770505071X

54. Paula JJ, Schlottfeldt CG, Moreira L, Cotta M, Bicalho MA, Romano-Silva MA, et al. Psychometric properties of a brief neuropsychological protocol for use in geriatric populations. Rev Psiquiatr Clín. 2010;37(6):251-5. https://doi.org/10.1590/S0101-60832010000600002

55. Atalaia-Silva KC, Lourenço RA. Tradução, adaptação e validação de construto do Teste do Relógio aplicado entre idosos no Brasil. Rev Saude Publica. 2008;42(5):930-7. https://doi.org/10.1590/S0034-89102008000500020

56. Teixeira Fabricio A, Aprahamian I, Sanches Yassuda M. Qualitative analysis of the Clock Drawing Test by educational level and cognitive profile. Arq Neuropsiquiatr. 2014 Apr;72(4):289-95. https://doi.org/10.1590/0004-282X20140004

57. de Paula JJ, Costa MV, de Andrade GF, Ávila RT, Malloy-Diniz LF; Paula JJd. Validity and reliability of a "simplified" version of the Taylor Complex Figure Test for the assessment of older adults with low formal education. Dement Neuropsychol. 2016 Jan-Mar;10(1):52-7. https://doi.org/10.1590/s1980-57642016dn10100010

58. Gómez F, Zunzunegui M, Lord C, Alvarado B, García A. Applicability of the MoCA-S test in populations with little education in Colombia. Int J Geriatr Psychiatry. 2013 Aug;28(8):813-20. https://doi.org/10.1002/gps.3885

59. Ribeiro Filho ST, Lourenço RA. The performance of the Mini-Cog in a sample of low educational level elderly. Dement Neuropsychol. 2009 Apr-Jun;3(2):81-7. https://doi.org/10.1590/S1980-57642009DN30200003

60. Carnero-Pardo C, Cruz-Orduña I, Espejo-Martínez B, Martos-Aparicio C, López-Alcalde S, Olazarán J. Utility of the mini-cog for detection of cognitive impairment in primary care: data from two Spanish studies. Int J Alzheimer Dis. 2013;2013:285462. https://doi.org/10.1155/2013/285462 